Journal of Money and Economy

Vol. 16, No. 3, Summer 2021

pp. 377-398

DOI: $10.29252 /$ jme.16.3.377

Original Research Article

\title{
Study on Gold as a Hedge or Safe Haven for the Stock Market by a Markov Switching Approach
}

\author{
Aghil Ariannejad* \\ Reza Tehrani $\uparrow$ \\ Received: 06 Jan 2021 \\ Approved: 07 Jul 2021
}

Although gold is no longer a central cornerstone of the international monetary and financial system, it still attracts considerable attention from researchers and investors. Nowadays, many investors manage their risk with valuable assets such as gold. This paper examines the dynamic relationships between gold and stock markets in the Tehran Stock Exchange. We have applied the Markov switching method to study the role of gold as a hedge or safe haven for the Tehran Stock Exchange risk from 1998 to 2018. The high dependence and low dependence regimes used in the Markov switching model are based on empirical results that show two regimes for all markets under investigation: a low volatility regime and a high volatility regime. The study's findings show that gold can act as a strong hedge and cannot act as a safe haven for risk of The Tehran stock exchange.

Keywords: Tehran Stock Exchange, Gold, Markov switching, Hedge, Safe haven JEL Classification: C24, G01, G10, G11

\section{Introduction}

Gold is one of the most brilliant g ductile, malleable, dense, conductive, nondestructive, and beautiful metals. This unique and unparalleled set of qualities has made it a coveted object throughout history by humans in almost every civilization, so there have been active gold markets for over 6000 years (Green 2007). The safe haven and hedge potentials of gold have been extensively analyzed in financial market fluctuations. Baur and Lucey (2010) are the first to formulate empirically testable definitions for a safe haven and a hedge. Although gold is no longer a central cornerstone of the international monetary and financial system, as 'an asset without a country' (Dooley et al., 1995), gold still attracts considerable attention from researchers and investors. The

\footnotetext{
* Department of Financial Management, Kish International Campus, University of Tehran, Kish, Iran; arian.aghil@gmail.com

$\dagger$ Department of Finance and Insurance, Faculty of Management, University of Tehran, Tehran, Iran; rtehrani@ut.ac.ir (Corresponding Author)
} 
increasing uncertainty of financial markets leads to diversifying a portfolio through hedging, and it becomes more and more important (Beckmann et al., 2015). In recent years, in most countries globally, including Iran, we can see financial market growth.

The growth of financial markets has increased the attractiveness of these markets for investment, but it has increased the risk of these markets as well. The emergence of a financial crisis in the last decade could be evidence of such a claim. The occurrence of an economic crisis, along with its harmful effects, causes researchers to seek solutions to prevent such crises in the future. After the financial crisis of 2008, many studies on risk in financial markets tried to provide a suitable strategy for dealing with risk in these markets. One of these strategies has been to consider gold as a safe haven or a hedge in the portfolios. There are many studies in this field with the growing attention to gold and its role in portfolio diversification. Especially since the global financial crisis in 2008, financial assets (in particular stock prices) showed losses while the gold price showed an intense increase. Figure 1 shows the Shanghai Stock Exchange (SSE) Composite Index fluctuations and the price of gold. Since the beginning of the financial crisis in 2007, the SSE Composite Index has fallen 38\%, while the gold price has risen $22 \%$ this year. The performance of gold is impressive and acceptable during the crisis.

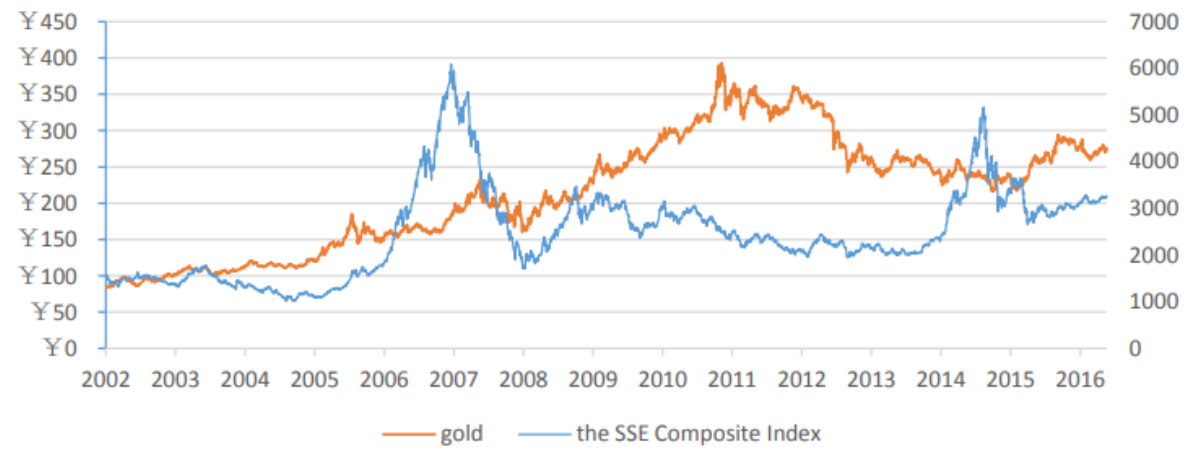

Figure 1. Price for gold and the Shanghai Stock Exchange (SSE) Composite Index ${ }^{1}$

1. Chen and Wang (2017) 
Among other financial assets, gold is an entirely unique asset that differs from other precious metals, including silver, platinum, and palladium (Batten et al., 2014).

Although Bretton Woods gold's breakdown is no longer a central cornerstone of the international monetary system, it still attracts significant attention from investors. Nowadays, diversifying a portfolio through hedging becomes more important since the uncertainty of financial markets is increasing so fast. Gold exhibits the function of a hedge or a safe haven as often referred to in the media and academia (Beckmann et al., 2015). Also, the financial media often refers to gold as a safe haven asset for portfolio investors. But, Baur and Lucey (2010) are the first to formulate empirically testable definitions for a hedge and a safe haven for financial assets such as bonds and stocks. Following their definitions, a hedge (safe haven) is an asset that is uncorrelated (negatively correlated) with another asset or portfolio on average (just in times of market turmoil or stress). Besides, the global financial and economic crisis that started in 2007 was an interesting experience that the gold price experienced an intense increase while other assets (in particular stock prices) exhibited losses (see Fig. 2).

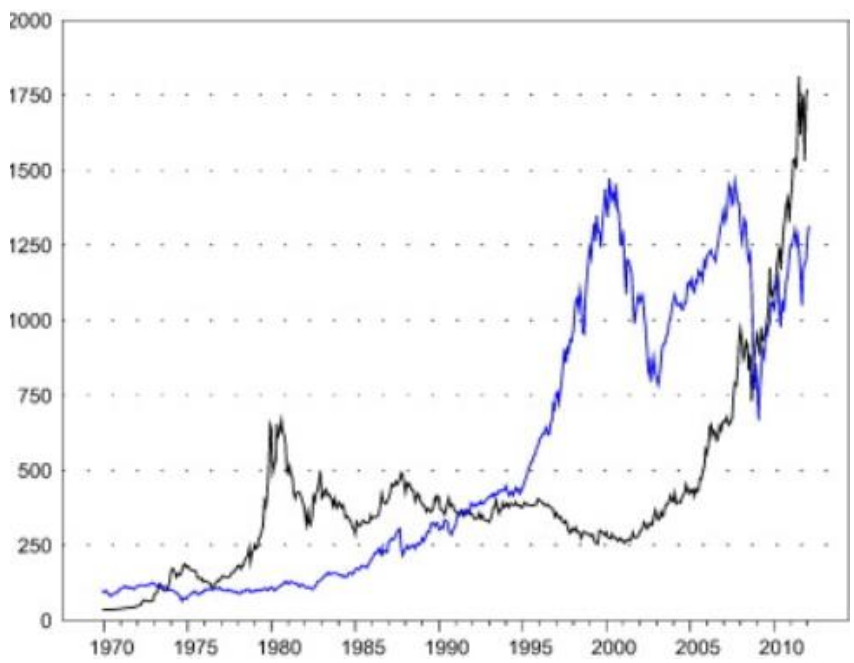

Figure 2. Gold prices (black line) and the US stock prices (blue line) both in the US dollar.

Source: goldprice.org 
In Figure 3, we can see the evolution of 10 Dow Jones industry indices (Such as Oil and Gas, Consumer goods, Telecom, Technology, Basic Materials, Healthcare, Utilities, Industrials, consumer services, and Financials) and gold price from 1979.12.31 until 2017.3.23

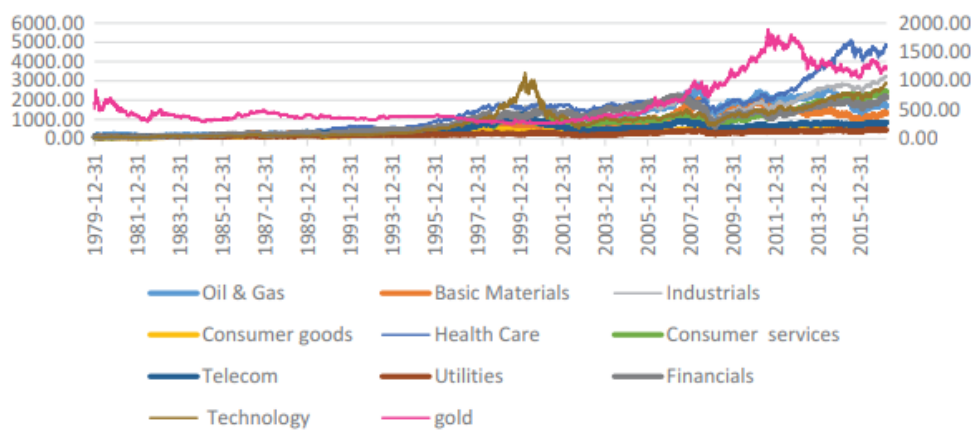

Figure 3. Fluctuations of 10 Dow Jones Industry Indices and Gold Price ${ }^{1}$

This figure shows that the Dow Jones industrial index is labeled on the left vertical axis, and the gold price is labeled on the right vertical axis. Moreover, the movements of each sequence are relatively stable before 1996 . While after 1996, the sequences begin to move and fluctuate considerably. So we can divide the whole period into two sub-periods: 1980.1.2-1995.12.29 and 1996.1.2-2017.3.23. By dividing the full period into two sub-periods, we find that: in a whole period (1980-2017), gold is not a hedge for Oil\&Gas, Basic Materials, and Utilities; gold is a safe haven for almost all sectors except Technology. While in sub-period I (1980-1995), gold does not operate as a hedge for Oil\&Gas; it is a strong safe haven for all assets. For sub-period II (1996-2017), gold does not act as a hedge for Oil\&Gas, Basic Materials, and Utilities and does not act as a safe haven for Oil\&Gas, Basic Materials, Utilities, Telecom, and Technology as well.

\section{Literature Review}

Gold seems to be appropriate to be considered as a hedge or a safe haven for portfolios. So, the role of gold in the global financial system is a significant topic for researchers. Also, gold was a so strong safe haven for the most

1 . Chen and Wang (2017) 
developed markets during the peak of the recent financial crisis (Baur and Lucy, 2010). It could be a zero-beta asset (McCown and Zimmerman, 2006). As a hedge or a safe haven for portfolios, gold seems an unavoidable asset. The reason is that, in contrast to many other commodities, gold is well-known to be durable, easily recognizable, storable, portable, divisible, and easily standardized (Baur, 2013). The relationship between a strong and a weak form of the hedge and the safe haven property is distinguished. The main question is whether a negative correlation of gold and stock returns occurs on average or in extreme market conditions. The former (latter) would indicate a solid hedge (safe haven) function of gold. It implies that the gold price increases after a fall of stock prices in such conditions and therefore compensate investors for losses incurred with stock investments (Baur and Lucy, 2010).

These days' financial markets and their instruments tend to overgrow both in volume and value (Baur and Lucey, 2010). The growth never comes with risks from the financial system, which at the same time drags the investors not only to hedge their investments but look for safe havens to avoid losses in case of tumultuous conditions. Baur and Lucey (2010) mentioned that the investment vehicles that could act as a hedge (safe haven) are expected to have a significant negative relationship with other investment solutions in ordinary conditions. Also, gold can be regarded as a safe haven against exchange rates in both countries, highlighting its monetary asset role (Ciner et al., 2013). In the Islamic stock market, gold could be a fragile hedge and a strong safe haven against extreme Islamic stock market movements, and it has significant implications for portfolio diversification and hedging strategy choice (Chkili, 2017). We have used the model of this article in this research. Gold can also hedge against stock losses in most cases, and its role as a safe haven or a hedge against stocks is undoubtedly important (Coudert and Raymond, 2011). Gold is not only a prominent safe and secure haven asset but risky compared to other safe haven assets such as US bonds such as government bonds. The financial crisis also exemplifies the role of the US dollar as a safe haven currency. Also, how can it mask the safe haven effect of gold? (Baur and McDermott, 2016).

Additionally, cryptocurrencies like Bitcoin can be safe- haven property. However, some questions come up like does Bitcoin exhibit a safe haven property for stock market investments, and is such property similar to or different from that of gold and the general commodity index. Each of these properties, such as Bitcoin, gold, and the commodity index, can be considered as a weak safe haven asset in some cases (Shahzad et al., 2019). Also, in comparing gold and Bitcoin, they have distinct safe haven and hedging 
characteristics (Shahzad et al., 2020). Both Bitcoin and gold can show the roles of a hedge, a safe haven, and a diversifier for oil price movements. However, this asset seems to be sensitive to Bitcoin's and gold's different market conditions (bear, normal, or bull) and whether the oil price is in a downside, normal, or upside regime (Selmi et al., 2018).

Moreover, gold and Crude oil are no more than weak safe haven assets for clean energy indicators. However, the superiority of crude oil to gold is evidenced in the case of infinitely extreme market movements (Elie et al., 2019). Besides, gold and the US dollar can show their significant role as a safe haven for emerging stocks; the US dollar is better than gold in most cases, while its superiority in hedging infinitely extreme risks is weakened in the subsample of the global crisis and the out-of-sample; and that the downside risk gains offered by the US dollars for China and Thailand are very interesting (Wen et al., 2018).

In another study, gold and silver show evidence of inflation-hedging ability, with the case being so much stronger for gold. Both metals' values are integrated with consumer prices, showing additional proof of hedging ability (McCown and Zimmerman, 2006). However, the hedge and safe haven properties of gold have a changing nature. In a whole period (1980-2017), gold is not a hedge for Oil and Gas, and gold is a safe haven for almost all sectors except the technology sector. While in sub-period I (1980-1995), gold is not a hedge for Oil and Gas; it is a strong safe haven for all sectors. In subperiod II (1996-2017), gold is not a hedge for Oil and Gas. Also, gold is not a safe haven for Oil and Gas, Basic Materials, Utilities, Telecom, and technology sections (Chen and Wang, 2019). In terms of effective hedging strategy Kumar, (2014) aimed at the first and second orders moment transmission between gold and Indian industrial sectors with an application of portfolio design and hedging effectiveness using generalized VAR-ADCCBVGARCH model. The findings show unidirectional significant return spillover from gold to stock sectors. The negative values of measured timevarying conditional correlations are mainly observed during periods of market turbulence and crisis, indicating the scope of portfolio diversification and hedging during these specific periods. In an important study, Chkili, (2016) examines the dynamic relationships between gold and stock markets using data for the BRICS counties. The findings suggest that adding gold to a stock portfolio enhances its risk-adjusted return.

This study can confirm the theory of loss aversion of Kahneman and Tversky (1979). Based on this theory, loss aversion is the tendency to prefer avoiding losses to acquiring equivalent gains. Some studies have suggested 
that losses are twice as powerful, psychologically, as gains. Investors are influenced by their own biases, and when they face huge losses, they are not willing to sell their assets in the stock market and turn it into gold. Hence, when large negative shocks occur in the stock market, people do not want to invest in the gold market. This study also has some similar results with some studies such as "Is gold a hedge or safe haven for Islamic stock market movements? Markov switching approach" by Chkili, (2017). Besides, no one has analyzed their volatility dynamic using a Markov switching approach for the Tehran stock exchange. Given our main objective, we choose the Tehran stock exchange to investigate the role of gold as a hedge and safe haven for such analysis that helps investors to acquire effective diversification benefits and downside risk reductions for the period from 1998 to 2018.

\section{Models and Methodology}

This paper aims to investigate, on the one hand, the dynamic behavior of stock markets. On the other hand, it is to verify whether gold can serve as a hedge or a safe haven for the considered stock markets. To achieve our objective, we estimate in the first step a Markov switching GARCH (MS-GARCH) model to investigate the dynamic volatility of the stock markets during the turbulent period 1998-2018. In the second step, we introduce the gold return variable in our Markov switching framework to test the property of gold as a hedge and a safe haven for the markets under investigation.

\subsection{GARCH Model}

The GARCH model is developed by Bollerslev (1986) to describe the conditional variance of the financial return series. Let $\mathrm{y}_{\mathrm{t}}$ be the Tehran stock exchange return series, the simple GARCH $(1,1)$ model may be presented as follows:

$y_{t}=\mu_{t}+\varnothing X_{t}+\varepsilon_{t}$

$\varepsilon_{t}=\sigma_{t} z_{t}, z_{t} \rightarrow$ iid $N(0,1)$

$\sigma_{t}^{2}=\omega+\alpha \varepsilon_{t-1}^{2}+\beta \sigma_{t-1}^{2}$

Where $\mu_{\mathrm{t}}$ and $\sigma_{\mathrm{t}}^{2}$ are the conditional mean and the conditional variance of stock returns, respectively. In the mean equation, we introduce the gold price changes measured by Xt to check the role of gold as a hedge for The Tehran stock exchange. 


\subsection{Markov Switching GARCH Model}

Given that our second objective is to investigate the safe haven effect of gold, we extend our analysis to verify the sort of relationship between the gold and stock markets during normal and turbulent periods. For this purpose, we use a two-state Markov switching approach. This approach is developed by Gray (1996) and Dueker (1997) and was recently used by Brunetti et al. (2008) and Guesmi et al. (2013). The Markov switching GARCH (MS-GARCH) model may be written as follows:

$$
\begin{aligned}
& y_{t}=\mu\left(s_{t}\right)+\emptyset\left(s_{t}\right) x_{t}+\varepsilon_{t} \\
& \varepsilon_{t}=\sigma\left(s_{t}\right) z_{t}, z_{t} \rightarrow \text { iid } N(o, 1) \\
& \sigma_{t}^{2}=\omega\left(s_{t}\right)+\alpha \varepsilon_{t-1}^{2}+\beta \sigma_{t-1}^{2}
\end{aligned}
$$

where $\mu\left(\mathrm{s}_{\mathrm{t}}\right)$ and $\sigma^{2}\left(\mathrm{~s}_{\mathrm{t}}\right)$ design respectively the conditional mean and the conditional variance depending on the regime at time $t$, represented by St. St is assumed to be a two-state Markov process that takes the values 1 or 2 with the following transition probability matrix:

$P=\left[\begin{array}{ll}p\left(s_{t}=0 \mid s_{\mathrm{t}-1}=0\right) & p\left(s_{t}=1 \mid s_{t-1}=0\right) \\ p\left(s_{t}=0 \mid s_{t-1}=1\right) & p\left(s_{t}=1 \mid s_{t-1}=1\right)\end{array}\right]=\left[\begin{array}{ll}p_{00} & p_{01} \\ p_{10} & p_{11}\end{array}\right]$

Using the Markov switching model, empirical results show two regimes for all markets under investigation: a low volatility regime and a high volatility regime. More interestingly, the periods of high volatility coincide with the major economic and political events that occurred during the period under study. According to Markov's switching approach, if in a high volatile regime, it is in line with critical market conditions; if the gold market volatility coefficient is negative (and significant), it means that gold is a strong safe haven for the stock market. Also, if this coefficient is negative (and significant) in the normal and volatile regime, it means that gold plays the role of (strong) risk coverage for the stock market. The question that arises is why the method used in this study has an advantage over previous methods. Van Norden and Schaller (1999), as the founder of this paradigm, shows that price behavior and stock market returns follow a nonlinear pattern. Van Norden and Schaller (1999) argue that there is a nonlinear relationship between economic fundamentals and stock prices and that small changes in economic fundamentals sometimes lead to large stock market shocks. He argues that price (or stock returns) follows a regime-changing behavior. His proposed method for modeling stock market prices is the Markov switching method, which allows us to easily model nonlinear stock market behavior. Now, in this 
research model, if we model the nonlinear behavior of the stock market with a linear model, we have naturally ignored part of the reality, and this issue, in addition to affecting the explanatory power of the model, can also affect the accuracy of the results. On the other hand, as explained earlier, to use the previous methods in this field, it is necessary to specify the q\% quantile exogenously to make the model nonlinear. Of course, this can be a matter of taste and also does not correspond to the existing facts. This study does not exogenously specify from which quantitative relationship the relationship between the gold market and stocks changes. Using the Markov switching method, we allow the data to decide where to change the regime (and even whether or not there is a change at all), and this naturally helps to make the results more accurate. Besides, in this study, the variance part of the equation is modeled nonlinearly. Naturally, if the variance is also nonlinear and we model it with a linear model, it will have a specified error, and the results we will get will be invalid.

\subsection{Data Description and Preliminary Analysis}

The dataset consists of 22 years of The Tehran stock exchange index. The choice of this market is motivated by several reasons. First, this is a new research, and we could not find same research. There are some researches like the study by Chkili (2017). Also, as noted by Naifar et al. (2016) and Shahzad et al. (2019), these markets constitute the first Islamic indices launched for investors seeking Sharia-compliant equities. These indices also are the most commonly used in the empirical studies of Islamic stocks. Moreover, the Dow Jones Islamic indices have an adequate time series for the Shariah-based stocks (Hammoudeh et al., 2014). In addition, no one has analyzed their volatility dynamic using a Markov switching approach for The Tehran stock exchange. Given our main objective, we choose The Tehran stock exchange to investigate the role of gold as a hedge and safe haven for such analysis helps investors to acquire effective diversification benefits and downside risk reductions for the period spans from 1998 to 2018.

Gold and stock return:

$$
r t=\ln \left(\frac{p t}{p t-1}\right)
$$

In this formula $\mathrm{r}_{\mathrm{t}}$ is market return (gold and stock) and in $t$ period and $\mathrm{P}_{\mathrm{t}}$ is price in $t$ period. Figure 4 and 5 show the monthly market return trend. 
As it is clear in Figure 4, stock market fluctuations or turbulence have been higher in some periods than in other periods. The first period was in 2003 which experienced its highest historical increase (in one month). The second period was in 2008, in which there was the greatest (monthly) decrease. As shown in this chart, in 2008, the total stock market index has decreased by more than $10 \%$ during one month. In 2012, 2013, 2015, and 2018, we can see an increase in fluctuations in the stock market. Fluctuations from 2012 to 2013 were mostly the result of sanctions and rising inflation expectations. In the remaining years, we also see fluctuations in the stock market. However, as shown in figure 4 , the monthly average of stock return was positive (1.8\% per month), and this indicates that it was positive for most fluctuations.

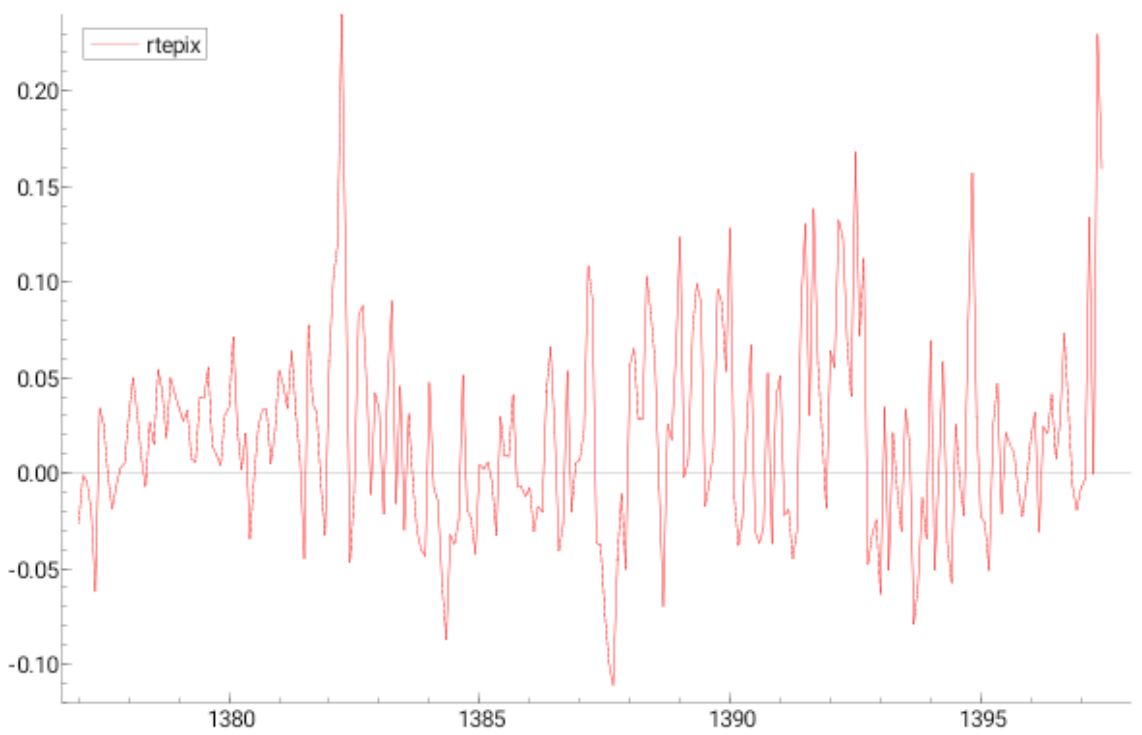

Figure 4. Stock market return.

Source: Research Findings.

In Figure 5, we can see fluctuations in gold market returns. As can be seen, before 2011, gold market fluctuations were limited. The reason was the dollar exchange rate's approximate stability between 2002 and 2011. The gold market's major fluctuations during this period are mainly due to changes in 
the global gold market. After 2011, the gold market fluctuations have increased sharply as a result of sanctions, and gold has recorded its highest historical (monthly) growth due to the sharp rise in the exchange rate and the increase in Gold price. In 2012, it has grown by more than 30\%. However, with the decrease in the gold price in the following years (from 2013), the most historical monthly decrease in gold was recorded in 2013. In 2018, based on the second round of sanctions, the gold market is on the rise again, and the fluctuations of this market have intensified.

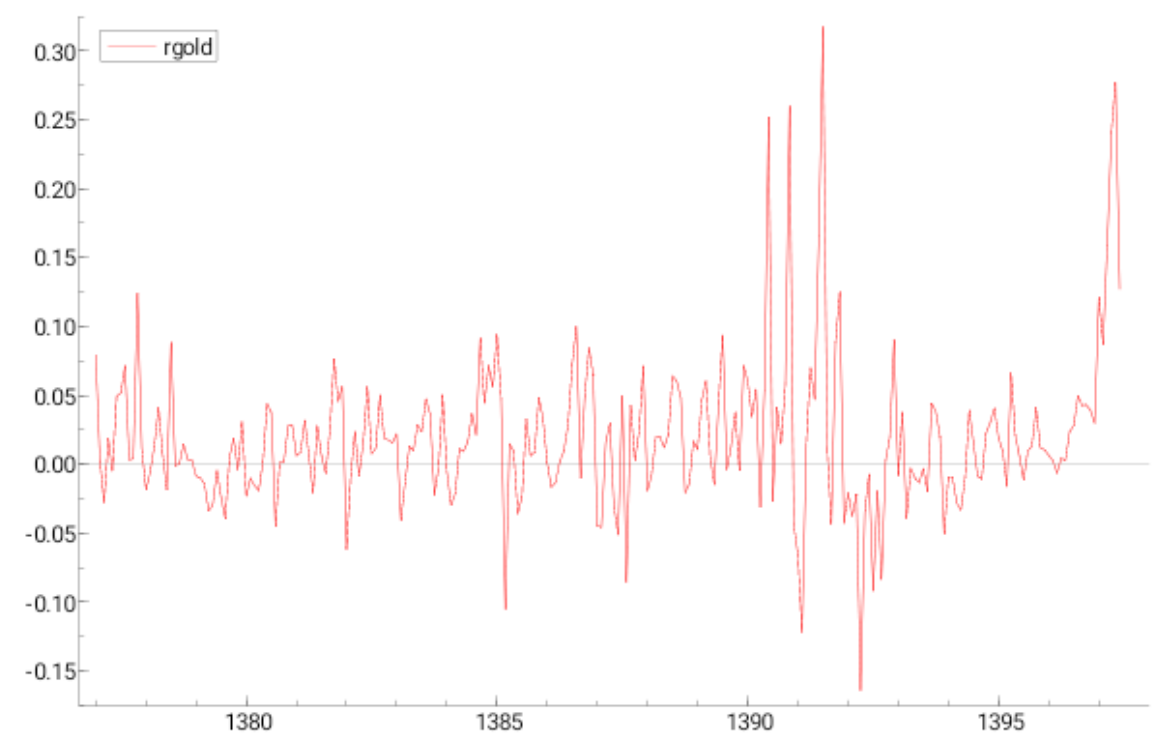

Figure 5. Gold return.

Source: Research Findings

Table 1 also shows the descriptive statistics of the research variables. Both assets have a positive monthly average return, indicating an increasing trend of these two assets over time. The highest monthly return was $31.8 \%$ for the gold market and $24 \%$ for the stock market. The lowest monthly return was $16.4 \%$ for the gold market and $-11.1 \%$ for the stock market. Both assets have positive skewness, indicating large positive shocks in both markets. There is another reason that the probability of occurrence of monthly returns below the 
average is higher than normal, which is asymmetrical distribution and is greater than $50 \%$. As expected, both assets have more Kurtosis than the normal and are separated from the Jarque-Bera test's normal distribution. It is an integral part of the financial markets. Higher Kurtosis in financial markets is due to the thicker distribution tail of financial market returns compared to the normal distribution, or in other words, due to the occurrence of large shocks.

Table 1

Descriptive statistics of the research variables

\begin{tabular}{lll}
\hline & Gold return & Stock return \\
\hline Mean & 1.9 & 1.8 \\
Max & 31.8 & 24.0 \\
Min & -16.4 & -11.1 \\
Standard deviation & 5.6 & 5.2 \\
Skewness & 1.8 & 0.9 \\
Kurtosis & 10.6 & 4.8 \\
Jarque-Bera & 742.0 & 67.8 \\
Probability value & 0.000 & 0.000 \\
\hline
\end{tabular}

Source: Research Findings

\section{Results and Discussion}

Gold prices continued their increasing trend during the major economic and geopolitical crises that occurred during the September 11 terrorist attack, the global financial crisis between 2007 and 2008, and the European debt crisis 2011-2012 (Chkili, 2016). In addition, the gold market reacts inversely to positive and negative shocks. So, positive shocks increase volatility more than negative shocks of equal magnitude (Baur, 2013).

The first step in time-series studies is to study the static variables used in the research. The variables' statics are important because unstable variables can lead to the formation of significant false relationships between variables and lead to incorrect conclusions by the researcher. Since this study uses the first-order difference of variables (in the logarithmic form) or market price returns, the variables are static, and false regression cannot be relevant.

The second issue is the nonlinearity of the model. Since this study uses the Markov-Garch nonlinear method and nonlinear models are inherently models that have many complexities in terms of estimating the parameters, it should be considered whether there is a need to use a nonlinear model or not? In other words, can a nonlinear model add to the explanatory power of the model? For this purpose, we can use the likelihood ratio (LR) test. This test compares the 
value of the orthogonal function of the nonlinear model with the linear model, and finally, we can comment on whether the nonlinear model has been able to significantly add to the explanatory power of the model. The results of this test are reported in Table 2.

Table 2

LR test results (nonlinear relationship test)

\begin{tabular}{lll}
\hline Probability value & Degrees of freedom & Statistic Value \\
\hline 0.000 & 9 & 72.247 \\
\hline
\end{tabular}

Source: Research Findings

The problem with the nonlinearity test using the LR test is that in the null hypothesis of this test, due to the presence of disturbing parameters, the asymptotic distribution of its statistic (likelihood ratio test statistic) is nonstandard.

Unfortunately, in this test's null hypothesis, the parameters $\mathrm{P}_{\mathrm{ij}}$ (transition probabilities) cannot be defined, and the information matrix is a single matrix. Ang and Bakaert (2002) showed that the asymptotic distribution of LR statistics between the two and one regimes could be approximated using the chi-square distribution so that the degree of freedom of this distribution is equal to the number of disturbing parameters plus the number of linear constraints applied. Therefore, in this research, this statistic is used to compare linear and nonlinear methods. Above all, the degree of freedom considered for the test is the number of constraints plus the annoying parameters. As the results of Table 2 shows, the value of the LR test statistic is greater than its critical value at a significance level of $1 \%$. As mentioned before, this test's null hypothesis shows the superiority of the linear model, and the opposite hypothesis shows the superiority of the Markov switching GARCH nonlinear model. Based on the results, it can be concluded that the null hypothesis is rejected, and instead of linear models, it is better to use Markov's nonlinear Marking switching method to estimate the model.

After ensuring that the relationship between the variables is nonlinear, the main research model in Equation 2 can be estimated. The estimation results of this model are reported in Table 3. To eliminate the possible autocorrelation, the proposed Newey-West approach has been used to estimate the standard deviation of the parameters.

After selecting the number of regimes, the accuracy of the model selection and the accuracy of the classification of the regimes can be tested based on the RCM index introduced by Ang and Bakaert (2002). The RCM index always 
has a number between 0 and 100 and can be extracted based on the following equation. In this relation, pt and (1-pt) probabilities are smoothed, and $\Omega T$ is the set of information about the whole sample. The closer the RCM is to zero, the more powerful the classification of the regime.

$R C M=400 \frac{1}{T} \sum_{t=1}^{T} \quad p(1-p)$

The general idea of the RCM index is that if the regimes' separation is done correctly, the value of smoothed probabilities will probably be close to one, and if the separation of the diets is not done with great accuracy, for a twodiet model, the odds are smooth (i.e., the model cannot correctly determine whether the data in question is in mode one or mode 2). It will cause the RCM index to go to zero when the regimes are separated correctly and to 100 when not done well. Table 3 shows the estimated RCM statistics obtained for the Markov switching model. As can be seen in this table, the value of the obtained RCM statistic is 14.73 , which is a low figure. It was explained above that the RCM value is always between zero and 100. The closer this number is to zero, the more accurate the separation of regimes. Accordingly, considering that on the scale of zero to 100 , the figure of 14.73 is relatively small, it seems that the separation of regimes was accurate, and the model was able to separate the two regimes well.

Table 3

The value of RCM statistics obtained for the estimated model

\section{RCM Statistics value}

\subsection{3}

Source: Research Findings

After ensuring that the relationship between the variables is nonlinear, the main research model in Equation 2 can be estimated. The estimation results of this model are reported in Table 4. To eliminate possible autocorrelation, the proposed Newey-West approach has been used to estimate the standard deviation of the parameters. The use of this variance-covariance matrix estimator ensures that even in the presence of autocorrelation, the standard deviation of the coefficients, the confidence intervals related to the coefficients as well as the t-statistic are valid, and the hypothesis tests of significance can be performed correctly. 
Table 4

Results of estimating the main research model $t$

\begin{tabular}{|c|c|c|c|c|}
\hline Coefficient & $\begin{array}{l}\text { Value of } \\
\text { Coefficient }\end{array}$ & $\begin{array}{l}\text { Standard } \\
\text { deviation }\end{array}$ & $\begin{array}{l}\text { Value of } t \\
\text { statistic }\end{array}$ & $\begin{array}{l}\text { Probability } \\
\text { value }\end{array}$ \\
\hline$\mu(1)$ & $0.03 * * *$ & 0.01 & 4.23 & 0.00 \\
\hline$\mu(2)$ & $-0 / 01$ & 0.01 & -0.61 & 0.54 \\
\hline$\varphi(1)$ & $-0.25 * * *$ & 0.07 & -3.41 & 0.00 \\
\hline$\varphi(2) \mid$ & $0.34 * * *$ & 0.11 & 3.23 & 0.00 \\
\hline
\end{tabular}

\begin{tabular}{lllll}
\hline \multicolumn{5}{c}{ Equation of variance } \\
\hline$\omega(1)$ & $0.01^{* *}$ & 0.00 & 2.14 & 0.03 \\
\hline$\omega(2)$ & $0.03^{* * *}$ & 0.01 & 3.97 & 0.00 \\
\hdashline$\alpha(1)$ & $0.01^{* *}$ & 0.05 & 2.22 & 0.03 \\
$\alpha \alpha(2)$ & $0.70^{* * *}$ & 0.22 & 3.12 & 0.00 \\
$\beta \beta(1)$ & $0.85^{* * *}$ & 0.05 & 16.20 & 0.00 \\
$\beta(2)$ & 0.01 & 0.26 & 0.04 & 0.97 \\
\hline
\end{tabular}

***: Significant at the level of one percent / **: Significant at the level of five percent $/ *$ : Significant at the level of ten percent

t: To eliminate possible autocorrelation, the proposed Newey-West approach has been used to estimate the parameters' standard deviation.

Source: Research Findings

Hamilton (1989) used the Markov Switching to model American business cycles. Hamilton used a dual regime MS-ARMA model in this study (classifying regime switches). In order to be able to interpret the regimes, he used the y-intercept sign. He has considered a regime whose y-intercept sign had a negative sign as a recession regime and a regime with the positive $y$ intercept sign as a growth regime. A similar approach is used here.

As the results in Table 4 show, the intercept of equation in the first regime is 0.03 , and the intercept of the variance equation in this regime is 0.01 . Also, the intercept of the mean equation in the second regime is -0.01 and the intercept of the variance equation in this regime is equal to 0.03 . Accordingly, the regime seems to correspond to periods when the stock market has yielded positive returns and low fluctuations. Regime II is also related to the period of market crisis, in which, in most cases, the market returns were negative, and the market fluctuated a lot. This can also be clearly seen in Figure 6. In this 
figure, the bar chart shows the stock market returns, and the periods marked in shades of gray are the periods in the second regime. As can be seen, regime two corresponds to periods when the market has fluctuated widely and has often had negative returns.
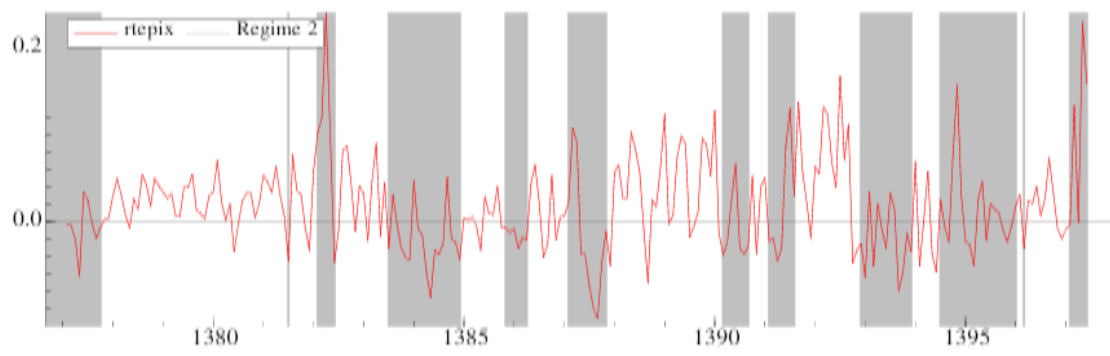

Figure 6. Separation of regimes.

Source: Research Findings.

Examining the coefficients related to the gold yield variable in diets one and two shows that the estimated value for this coefficient in the diet is -0.25 and in the diet is 0.34 . Also, according to Table 4, both coefficients are significant at the level of one percent. Given that the variable rate of return on gold in the regime is negative and significant, it can be concluded that gold is a strong risk hedge for the stock market. Of course, in the two regimes, there is no such negative relationship between these two variables. Therefore, gold cannot be considered as a strong safe haven for the stock market. Also, given that the estimated coefficient is positive and significant, the gold market is not even a weak safe haven for the stock market.

Table 5 shows the probabilities of regime-related transition. As shown in the table, the probability of transition from diet one to diet one was approximately 0.9 , and the probability of transition from diet two to twice was 0.87 . It shows that the stability of regime one is more than regime two. In other words, when we a $\div$ re in regime one, we will most likely (nearly $90 \%$ ) be in regime one in the next period (or the normal market period), and the probability of transition to the critical regime will be about $10 \%$. 
Table 5

Transition probabilities

\begin{tabular}{lll}
\hline & Regime 1 $(t$ period $)$ & Regime 2 $(t$ period $)$ \\
\hline Regime 1 $(\mathrm{t}+1$ period) & 0.9 & 0.13 \\
Regime 2 $(\mathrm{t}+1$ period) & 0.1 & 0.87 \\
\hline
\end{tabular}

Source: Research Findings

Does adding gold to the portfolio reduce portfolio risk? After it has been shown that gold is a strong risk hedge for the stock market, in this section, we now answer the question of whether adding gold to the stock portfolio reduces the risk of the portfolio or not. For this purpose, the general formula of portfolio risk is used. According to the theory, the variance of a portfolio, provided that it consists of two assets, can be calculated from the following simple formula:

$$
\sigma_{p}^{2}=\omega_{1}^{2} \sigma_{1}^{2}+\left(1-\omega_{1}\right)^{2} \sigma_{2}^{2}+2 \omega_{1}\left(1-\omega_{1}\right) \sigma_{1} \sigma_{2} \rho_{12}
$$

Where $\sigma_{p}^{2}$ the variance of portfolio returns $\sigma_{1}^{2}$ is the variance of stock returns, $\sigma_{2}^{2}$ the variance of gold returns $\omega_{1}$ is the share of stocks in the portfolio and $\rho_{12}$ is the correlation between the returns of gold and stocks. As shown above, the problem is the relationship between the gold market and the stock market follows a nonlinear pattern. Therefore, the linear correlation in the above formula $\left(\rho_{12}\right)$ will be invalid. Batten et al. (2014) uses scenario building to evaluate the effect of adding gold to a portfolio. In this study, this approach is used to overcome the nonlinearity of the correlation between the two assets. The previous section shows that normally in the stock market, there is a negative correlation between the stock market and the gold market. But we do not know what the size of this correlation exactly is. For this purpose, three levels of weak correlation $(-0.1)$, moderate correlation $(-0.5)$, and strong correlation (-0.9) are considered. Since the share of shares in the total portfolio also changes the final result, six scenarios are considered for shares. In the first scenario, gold is not invested, and all assets are allocated to stocks. In the second scenario, 0.8 is invested in stocks, and 0.2 is invested in gold, and in the last scenario, the largest portion of the portfolio is allocated to gold, and only 0.1 portfolios are allocated to stocks. 
Table 6

Risk (variance) of the stock portfolio in different scenarios

\begin{tabular}{|c|cccc}
\multicolumn{1}{c}{} & & \multicolumn{3}{c}{ Intensity of correlation } \\
\cline { 3 - 5 } & 1 & -0.1 & -0.5 & -0.9 \\
Shares & 0.8 & 27.3 & 27.3 & 27.3 \\
of the stock & 0.6 & 17.8 & 14.1 & 10.4 \\
in the & 0.4 & 13.4 & 7.8 & 2.2 \\
portfolio & 0.2 & 14.1 & 8.5 & 2.9 \\
& 0.1 & 19.9 & 16.2 & 12.5 \\
& 0.1 & 24.8 & 22.7 & 20.6 \\
\hline
\end{tabular}

Source: Research Findings

Table 6 shows the portfolio risk in each of the above scenarios. As can be seen in this table, in the case of investing only in stocks, the portfolio risk will be 27.3, which is the highest amount of risk among all scenarios. This result shows that adding gold in any quantity and with any size of negative correlation can reduce the portfolio's overall risk. Among the scenarios listed in Table 6, the lowest risk is related to the situation where $60 \%$ of the assets are invested in stocks, and the remaining $40 \%$ is allocated to gold. Also, when there is a very strong negative correlation between gold and stocks, the overall portfolio risk will be minimized.

\section{Conclusion}

The safe haven and hedge properties of gold have a changing nature. Whether gold can be used as a hedging instrument for stock indicators could differ in accordance with the characteristic of the sector and vary with time. The main purpose of this study was to answer two important questions in the field of investing in financial markets, and that was "Can the gold market serve as a cover for risk for the stock market? "And can the gold market act as a safe haven for it in times of the stock market crisis?" In this regard, to answer these questions, the monthly data of gold and stock markets in the period from April 1998 to September 2018 and the Markov switching method of GARCH were used to analyze these data. Using the Markov switching model, Empirical results show two regimes for all markets under investigation: a low volatility regime and a high volatility regime. The advantage of this method compared to other methods used in previous studies is that in this method, financial crises are not externally imposed by the researcher on the model, and the model recognizes crisis periods based on the nature of the data. It makes the results of this study more accurate than previous studies. 
The results of model estimation indicate that the gold, in the normal period of the stock market, plays the role of a strong hedge for stock market risk. Still, in this market crisis, gold (even at a weak level) cannot be a safe haven for the stock market. This result shows that when the market is normal and with little fluctuations, investors are willing to take part of their assets out of stock and add gold to their portfolio to reduce the risk of small losses; But they do not do the same way when they face huge losses in the market. This result can confirm the theory of loss aversion of. Kahneman and Tversky (1979). Based on this theory, loss aversion is the tendency to prefer avoiding losses to acquiring equivalent gains. Some studies have suggested that losses are twice as powerful, psychologically, as gains. Investors are influenced by their own biases, and when they face huge losses, they are not willing to sell their assets in the stock market and turn it into gold. Hence, when large negative shocks occur in the stock market, people do not want to invest in the gold market.

Another point is that in the stock market crisis, the gold market returns have also declined. This issue can be analyzed through the relationship between the foreign exchange market and the stock and gold markets. In the Iranian economy, one of the most important factors that affect gold price, along with domestic supply and demand and the global price of gold, is exchange rate fluctuations or turbulence. The experiences of the past years in the Iranian economy show a positive relationship between the foreign exchange market and the stock market; this is especially clearer when large changes (positive and negative) occur in the exchange rate. The reason is that large changes in exchange rates greatly affect stock-based export companies' income, such as petrochemicals and metals, etc. And because these companies are huge in the stock market, the stock market index is severely affected by exchange rate fluctuations. In other words, when the exchange rate falls sharply, both the stock market and the gold market simultaneously have significant declines. It ultimately leads to a positive correlation between the stock market and the gold market in times of crisis, and it causes both markets to enter a recession at the same time.

The results of examining the addition of gold to the portfolio also show that holding gold alongside stocks reduces the portfolio's overall risk. When there is a strong negative correlation between these two assets, the overall portfolio risk is significantly reduced. The negative correlation between the stock market and gold is high during the stock market's normal period. Therefore, during this period, adding gold to the portfolio improves the portfolio's performance. 
The results of this study have important policy implications, especially for investors. Suppose investors are active in the stock market. In that case, they can have gold in their portfolio to maintain the value of their assets when the stock market is declining (but not in a financial crisis) because gold is a strong risk hedge for the stock market. Investors should also be aware that they need to get gold out of their portfolios in times of crisis immediately because the movement of the stock market and the gold market is in the same direction when the stock market is in a volatile and crisis.

\section{References}

Ang, A., \& Bekaert, G. (2002). Regime Switches in Interest Rates. Journal of Business \& Economic Statistics, 20(2), 163-182.

Batten, J. A., Ciner, C., \& Lucey, B. M. (2014). On the Economic Determinants of the Gold-Inflation Relation. Resources Policy 41: 101-08

Baur, D. G., \& Lucey, B. M. (2010). Is Gold a Hedge or a Safe Haven? An Analysis of Stocks, Bonds and Gold. Financial Review, 45(2), 217-229.

Baur, D. G. (2013). Gold-Fundamental Drivers and Asset Allocation. Business School - Finance University of Technology, Sydney.

Baur, D. G., \& McDermott, T. K. (2016). Why is Gold a Safe Haven? Journal of Behavioral and Experimental Finance, 10, 63-71.

Beckmann, J., Berger, T., \& Czudaj, R. (2015). Does Gold Act As a Hedge or a Safe Haven for Stocks? A Smooth Transition Approaches. Economic Modelling, 48, 16- 24.

Bollerslev, T. (1986). Generalized Autoregressive Conditional Heteroskedasticity. Journal of Econometrics, 31(3), 307-327.

Brunetti, C., Scotti, C., Mariano, R. S., \& Tan, A. H. (2008). Markov Switching GARCH Models of Currency Turmoil in Southeast Asia. Emerging Markets Review, 9(2), 104-128.

Chkili, W. (2016). Dynamic Correlations and Hedging Effectiveness between Gold and Stock Markets: Evidence for BRICS Countries. Research in International Business and Finance, 38, 22-34.

Chkili, W. (2017). Is Gold a Hedge or Safe Haven for Islamic Stock Market Movements? A Markov Switching Approach. Journal of Multinational Financial Management, 42, 152-163.

Chen, K., \& Wang, M. (2017). Does Gold Act as a Hedge and a Safe Haven for China's Stock Market? International Journal of Financial Studies, 5(3), 18.

Chen, K., \& Wang, M. (2019). Is Gold a Hedge and Safe Haven for Stock Market? Applied Economics Letters, 26(13), 1080-1086.

Ciner, C., Gurdgiev, C., \& Lucey, B. M. (2013). Hedges and Safe Havens: An Examination of Stocks, Bonds, Gold, Oil and Exchange Rates. International Review of Financial Analysis, 29, 202-211. 
Coudert, V., \& Raymond, H. (2011). Gold and Financial Assets: Are There Any Safe Havens in Bear Markets. Economics Bulletin, 31(2), 1613-1622.

Dooley, M. P., Isard, P., \& Taylor, M. P. (1995). Exchange Rates, Country Preferences and Gold [J]. Applied Financial Economics, 5, 121-129.

Dueker, M. J. (1997). Markov Switching in GARCH Processes and Mean-Reverting Stock-Market Volatility. Journal of Business \& Economic Statistics, 15(1), 2634.

Elie, B., Naji, J., Dutta, A., \& Uddin, G. S. (2019). Gold and Crude Oil as Safe Haven Assets for Clean Energy Stock Indices: Blended Copulas Approach. Energy, 178, 544-553.

Gray, S. (1996). Modeling the Conditional Distribution of Interest Rates as a RegimeSwitching Process. Journal of Financial Economics 42, 27-62.

Green, T. A. (2007). Gold Electrodeposition for Microelectronic, Optoelectronic and Microsystem Applications. Gold Bulletin, 40(2), 105-114.

Guesmi, K., Akbar, F., Kazi, I. A., \& Chkili, W. (2013). Jump Dynamics and Volatility Components for OECD Stock Returns. Journal of Applied Business Research (JABR), 29(3), 777-792.

Hamilton, J. D. (1989). A New Approach to the Economic Analysis of Nonstationary Time Series and the Business Cycle. Econometrica: Journal of the Econometric Society, 357-384.

Hammoudeh, S., Mensi, W., Reboredo, J.C., \& Nguyen, D.K., (2014). Dynamic Dependence of the Global Islamic Equity Index with Global Conventional Equity Market Indices and Risk Factors. Pacific-Basin Finance Journal. 30, 189-206.

Kahneman, D., \& Tversky, A. (1979). Prospect Theory: An Analysis of Decision under Risk. Econometrics, 47, 263-291. Recuperado de http://www. jstor. org/pss/1914185.

Kumar, D. (2014). Return and Volatility Transmission between Gold and Stock Sectors: Application of Portfolio Management and Hedging Effectiveness. IIMB Management Review, 26(1), 5-16.

McCown, J. R., \& Zimmerman, J. R. (2006). Is Gold a Zero-Beta Asset? Analysis of the Investment Potential of Precious Metals. Analysis of the Investment Potential of Precious Metals, Vol 15.

Naifar, N., Hammoudeh, S., \& Al Dohaiman, MS, (2016). Dependence Structure between Sukuk (Islamic bonds) and Stock Market Conditions: An Empirical Analysis with Archimedean copulas. J. Int. Financ. Mark. Inst. Money 44, 148 165.

Shahzad, S. J. H., Bouri, E., Roubaud, D., Kristoufek, L., \& Lucey, B. (2019). Is Bitcoin a Better Safe-haven Investment than Gold and Commodities? International Review of Financial Analysis, 63, 322-330.

Shahzad, S. J. H., Bouri, E., Roubaud, D., \& Kristoufek, L. (2020). Safe Haven, Hedge and Diversification for G7 Stock Markets: Gold versus Bitcoin. Economic Modelling, 87, 212-224. 
Selmi, R., Mensi, W., Hammoudeh, S., \& Bouoiyour, J. (2018). Is Bitcoin a Hedge, a Safe Haven or a Diversifier for Oil Price Movements? A Comparison with Gold. Energy Economics, 74, 787-801.

Van Norden, S., \& Schaller, H. (1999). Speculative Behavior, Regime-Switching, and Stock Market Crashes. In Nonlinear Time Series Analysis of Economic and Financial Data (pp. 321-356). Springer, Boston, MA.

Wen, X., \& Cheng, H. (2018). Which Is the Safe Haven for Emerging Stock Markets, Gold or the US Dollar? Emerging Markets Review, 35, 69-90. 